\title{
Sedation and Lumbar Punctures for Pediatric Leukemia Patients: The Challenge of Unintended Consequences
}

Peter Shaw ${ }^{1}$

${ }^{1}$ All Children's Hospital

September 25, 2021

\section{Hosted file}

PBC Highlight 8-1-21.docx available at https://authorea.com/users/436329/articles/538722sedation-and-lumbar-punctures-for-pediatric-leukemia-patients-the-challenge-ofunintended-consequences 